\title{
Sustainable graphitic carbon materials from biogas as anodes for sodium-ion batteries
}

\author{
Ignacio Cameán`, Jorge Rodríguez-García, and Ana B. García \\ Instituto Nacional del Carbón (CSIC), Francisco Pintado Fe 26, 33011 Oviedo, \\ Spain
}

\begin{abstract}
Novel graphitic materials of renewable origin, biogas-derived carbon nanofibers (BCNFs), are investigated as anodes for sodium-ion batteries in a glyme-based electrolyte. These materials show a unique combination of electrochemical properties, including suitable capacity $\left(\sim 100 \mathrm{mAh} \mathrm{\textrm {g } ^ { - 1 }}\right)$, high rate capability, excellent cycle stability and coulombic efficiency as well as long cycle life ( 6000 cycles up to $7.5 \mathrm{~A} \mathrm{~g}^{-1}$ ) which make them adequate candidates for this application. The sodiation of BCNFs occurs through different combinations of diffusioncontrolled intercalation and capacitive intercalation processes. Overall, the quantitative contribution of the capacitive current to the total stored sodium in BCNF electrodes is noteworthy (28-71\%), which account for their ultrahigh rate performance, comparable to that of supercapacitors, because of the improvement of the transportability of the $\mathrm{Na}^{+}$ions through the graphene layers.
\end{abstract}

\footnotetext{
* Corresponding author

E-mail address: icamean@incar.csic.es
} 


\section{Introduction}

All sectors of modern society agree about the need for reducing the widespread use of fossil fuels as energy sources because of the non-renewable nature as well as the associated environmental pollution. To tackle this challenge, the attention has been focused on electricity generation from renewable energy sources, which are discontinuous and stochastic, and therefore, it requires of highly-efficient large-scale electrical energy storage (EES) systems. Among them, lithium-ion batteries (LIBs) are being used in EES systems from wind and solar energies. ${ }^{1}$ Concerning batteries application in these systems which are formed by a large number of units, sodium-ion batteries (SIBs) are an interesting alternative to LIBs, because of the much greater abundance of sodium in earth and lower cost as compared with lithium as well as its eco-friendly nature. ${ }^{2}$ In this context, a large number of electrode materials for SIBs have been investigated in the last five years. ${ }^{3-9}$ In particularly, research on cathodic materials is advancing very fast since several of them, such as transition-metal oxides and polyanionic compounds, simply replace lithium by sodium in analogue compounds and, therefore, it is benefiting from more than 30 years of R\&D in LIBs. Similarly, the electrolytes for SIBs are formed mainly for sodium salts dissolved in organic carbonates or, in some cases, in ionic liquids. ${ }^{10-12}$ In contrast, sodium ions hardly intercalates into graphite - the anode choice par excellence in LIBs - during the electrochemical process, preventing the use of this material as anode for SIBs. Therefore, the formation of binary intercalation compounds (b-GIC) was found to be limited to $\mathrm{NaC}_{64}$ which corresponds to a capacity value of only $\sim 35 \mathrm{mAh} \mathrm{g}^{-1}$, against the $\mathrm{LiC}_{6}$ b-GIC compound obtained for $\mathrm{Li}^{+}$ions $\left(372 \mathrm{mAh} \mathrm{g}{ }^{-1}\right) \cdot{ }^{13,14}$ Based on a first- 
principles study of the alkali metal-graphite intercalation compounds, this limitation is due to the energetic instability of the Na-GIC as a result of the stress induced in the graphite structure when some $\mathrm{Na}^{+}$ions are intercalated. ${ }^{15}$ This problem has been effectively avoided by using ether-based electrolytes which solvate the $\mathrm{Na}^{+}$ ions, thus allowing the co-intercalation of these species to form stable ternary graphite intercalation compounds (t-GIC). In this way, reversible capacities values in the interval 100-150 $\mathrm{mAh} \mathrm{g}^{-1}$ with capacity retention and coulombic efficiency around $100 \%$ along with excellent rate capability were obtained for SIBs with graphite anodes in electrolytes formed by various sodium salts in glyme-based solvents (mono-, di-, tri-, tetra-glymes). ${ }^{16-21}$ Moreover, graphitic materials other than stricto sensu graphite, such as coal-based graphitic carbon foams, were also investigated as anodes for SIBs using glyme-based electrolytes. These graphitic materials showed suitable capacity with remarkable cycle stability and performance at high electrical current densities. ${ }^{22}$ These results have demonstrated that graphite (synthetic and natural) is a promising anode for SIBs, providing appropriate cathodic materials are used. ${ }^{17-24}$ However, given that synthetic graphite (up to $43 \%$ of current LIBs market) ${ }^{25}$ is worldwide mainly prepared from petroleum coke, its implementation in devices for the storage of renewable energy would be an inconsistency.

Based on these findings and searching for an ideal SIBs anodic material from the points of view of efficiency and source, graphitic biogas-derived carbon nanofibers (BCNFs) are herein considered for the first time. Biogas is a renewable energy source which is currently used in co-generation combustion plants for the production of heat and electricity. Nevertheless, the exploitation of biogas for different applications such as the catalytic decomposition of biogas to 
simultaneously produce syngas and BCNFs seems to be an interesting option. ${ }^{26}$ Furthermore, BCNFs can be subjected to heat treatment at high temperature $(\geq$ $2400{ }^{\circ} \mathrm{C}$ ), in an inert atmosphere, to achieve their transformation into graphitic nanofibers with high degree of three-dimensional structural order. ${ }^{27}$ Thus, BCNFs with crystalline parameters values $\left(\mathrm{d}_{002} \sim 0.3360 \mathrm{~nm}, \mathrm{~L}_{\mathrm{c}} \sim 48 \mathrm{~nm}, \mathrm{~L}_{\mathrm{a}} \sim>100 \mathrm{~nm}\right)$ and porosity $\left(\mathrm{S}_{\mathrm{BET}} \sim 21 \mathrm{~m}^{2} \mathrm{~g}^{-1}\right)$ comparable to oil-derived synthetic graphite were prepared by our research group. These graphitic nanomaterials were further successfully applied as anodes for LIBs. ${ }^{28}$ In this work, the performance as anodes in SIBs of several graphitic BCNFs of different degree of three-dimensional structural order is investigated by prolonged galvanostatic cycling versus $\mathrm{Na} / \mathrm{Na}^{+}$ at low (18.6 $\mathrm{mA} \mathrm{g}^{-1}$ ) and high (up to $7.5 \mathrm{~A} \mathrm{~g}^{-1}$ ) electrical current densities, using a glyme-based electrolyte, sodium triflate (sodium trifluoromethanesulfonate, $\mathrm{NaOTf}$ ) in diglyme (diethylene glycol dimethyl ether, DG). The results are discussed on the basis of battery reversible capacity, irreversible capacity in the initial cycle, capacity retention along cycling, and cycling efficiency values. Moreover, the influence of electrical current density on both electrode sodiation capacity and cycle life is also studied. The mechanism of $\mathrm{Na}^{+}$ions - BCNFs interaction is as well analyzed through cyclic voltammetry experiments, following a method based on the relationship between peaks current and scan rate. ${ }^{29}$ From this analysis, the contributions of diffusion-controlled intercalation and capacitive reactions, which occur during the electrochemical storage of sodium in graphite, ${ }^{19}$ to the sodiation capacity of BCNF electrodes, in the whole range of potential, are assessed. 


\section{Experimental}

Graphitic BCNFs: source, preparation and characterization. Four different BCNFs from the catalytic decomposition of biogas were heat treated at $2600{ }^{\circ} \mathrm{C}$ or $2800{ }^{\circ} \mathrm{C}$ using a graphite electrical furnace for $1 \mathrm{~h}$ in argon flow. The graphitized BCNFs (11 in total) thus prepared were named by adding a suffix with the temperature in the BCNF precursor designation (e.g. BCNF16), such as BCNF16/26. The experimental set up and BCNF characteristics can be found in. ${ }^{27}$

The structural characterization of the graphitized BCNFs was carried out by means of X-ray Diffraction using a Bruker D8 powder diffractometer, as described elsewhere. ${ }^{30}$ The crystalline parameters: $d_{002}$, interlayer distance, and $L_{c}$ and $L_{a}$, crystallite sizes along $c$ and a axes, respectively, were determined from the XRD profiles (see Figure S1 of Supporting Information) and used for the assessment of BCNFs graphitic degree. ${ }^{31}$ Bragg's equation was applied to (002) peak for the determination of $d_{002}$, whereas $L_{c}$ and $L_{a}$ were obtained from (002) and (110) peaks, respectively, by the Scherrer formula with $\mathrm{K}$ values of 0.9 for $L_{c}$ and 1.84 for $\mathrm{L}_{\mathrm{a}} \cdot{ }^{32}$ Crystalline parameters standard errors are $<0.06 \%$ for $\mathrm{d}_{002}$, and $<3 \%$ and $<5 \%$ for $L_{c}$ and $L_{a}$, respectively. A Silicon standard was used to correct the broadening of the diffraction peaks caused by instrumental factors.

The specific surface areas $\left(\mathrm{S}_{\mathrm{BET}}\right)$ of the BCNFs were determined by $\mathrm{N}_{2}$ adsorption-desorption at $-196{ }^{\circ} \mathrm{C}$, in a Micromeritics ASAP 2420 volumetric adsorption system, after they were degassed at $250{ }^{\circ} \mathrm{C}$ overnight. The calculation of the $\mathrm{S}_{\mathrm{BET}}$ values was carried out applying the Brunauer-Emmett-Teller (BET) method and taking a cross sectional area of the $\mathrm{N}_{2}$-adsorbed molecule of 0.162 
$n m^{2}$. The amount of $N_{2}$ absorbed at relative pressure $\left(p / p^{0}\right)$ of 0.97 was considered as the total pore volume of the materials.

Cells preparation and electrochemical measurements. Two- and threeelectrode Swagelok-type cells were used for evaluating the performance as anodes in sodium-ion batteries of the graphitic BCNFs. The working electrode was prepared from the slurry obtained by stirring vigorously (over $20 \mathrm{~h}$ ) a mixture of 80 wt. $\%$ of the active material (BCNFs) and 20 wt.\% of a polyvinylidene fluoride (PVDF) solution, used as binder, in 1-methyl-2-pirrrolidone. Afterwards, one drop of this slurry was spread on a copper disc of $12 \mathrm{~mm}$ of diameter and $25 \mu \mathrm{m}$ of thickness, vacuum dried at $120{ }^{\circ} \mathrm{C}$ during, at least, $2 \mathrm{~h}$ and, finally, pressed at $\sim 40$ MPa with a hydraulic press. The loads (active material + binder) of the different BCNFs-based working electrodes are provided in Table SI of the Supporting Information. Both the counter electrode and the reference electrode (threeelectrode cell configuration) were metallic sodium discs of $12 \mathrm{~mm}$ diameter. Two micro-fiber glass discs soaked with the electrolyte, a solution $1 \mathrm{M}$ of sodium triflate (sodium trifluoromethanesulfonate, NaOTf) in dyglime (diethylene glycol dimethyl ether, DG) were placed between electrodes. The preparation of the electrolyte was carried out in a glove box under Ar atmosphere, with oxygen and water contents < $0.1 \mathrm{ppm}$, by magnetic stirring. A $4 \mathrm{~A}$ zeolite type was afterwards added to the electrolyte to eliminate any residual water. The cells were also assembled in the glove box being the initial potential in the range $2.8-3.0 \mathrm{~V}$ vs $\mathrm{Na} / \mathrm{Na}+$. Both the NaOTf salt (> $98 \%$ purity) and the DG solvent (anhydrous, $99.5 \%$ ) were provided by Aldrich. 
The electrochemical tests of the cells were performed in a Biologic VMP2 potentiostat/galvanostat. Two-electrode cells were subjected to different

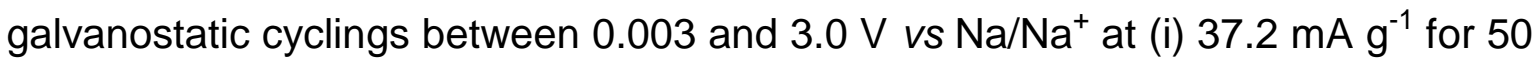
cycles; (ii) 6 consecutive different electrical current densities from 18.6 to $744 \mathrm{~mA}$ $\mathrm{g}^{-1}, 10$ cycles each current, starting and finishing at $18.6 \mathrm{~mA} \mathrm{~g}^{-1}$ and (iii) up to 6000 cycles at high electrical current densities (1.86 $\mathrm{A} \mathrm{g}^{-1}, 3.72 \mathrm{~A} \mathrm{~g}^{-1}$ and $\left.7.44 \mathrm{~A} \mathrm{~g}^{-1}\right)$. Three-electrode cells were used for the cyclic voltammetry experiments at different scan rates $\left(0.2,0.5,1.0,1.5,2.0\right.$ and $\left.3.0 \mathrm{mV} \mathrm{s}^{-1}\right)$ for 3 cycles in the $0.003-3.0 \mathrm{~V} v \mathrm{~s}$ $\mathrm{Na} / \mathrm{Na}^{+}$range.

\section{Results and Dicussion}

\section{Mechanism of electrochemical storage of $\mathrm{Na}^{+}$ions into the graphitic} BCNFs. The potential profiles (E vs $\mathrm{Na} / \mathrm{Na}^{+}$against capacity) from the galvanostatic cycling at $37.2 \mathrm{~mA} \mathrm{~g}^{-1}$ of BCNF electrodes in the diglyme-based electrolyte $(\mathrm{NaOTf} / \mathrm{DG})$ are firstly analyzed. Four regions can be observed in these profiles, specifically from high to low potential, a very sharp drop (I), a more or less sloping plateau (II) and a basically flat plateau (III) which is followed by a sloping curve (IV). As an example, Figure 1 shows the potential profiles of BCNF161/28, BCNF165/28, BCNF175/28 and BCNF177/28 electrodes for cycles 1, 2 and 25 in which these regions are clearly distinguished (potential profiles for the other electrodes are provided in Figure S2 of Supporting Information). Focusing on the sodiation (discharge) profiles, in particular in region I, the potential falls sharply to $\sim 1.00 \mathrm{~V}$ in the first cycle and to $1.05-1.10 \mathrm{~V}$ in the subsequent cycles without slope differences. Therefore, SEI formation on BCNF electrodes surface during 
the first discharge cycle appears negligible. In this respect, evidences of SEI-thin 16-19, 21 and even SEl-free ${ }^{33}$ graphite anodes in similar glyme-based electrolytes were reported. Potentials from these to $\sim 0.70 \mathrm{~V}$ vs $\mathrm{Na} / \mathrm{Na}^{+}$were determined for the sloping plateau (II) of BCNF electrodes. That shift to a slightly higher potential, which can be better appreciated in the corresponding differential capacity plots (Figure 1), was also observed in the profiles of graphite electrodes in different glyme-based electrolytes. ${ }^{18}$ In a recent work, Maibach et al. ${ }^{34}$ explained that this behavior could be a consequence of the deformation of the graphite lattice structure causes by $\mathrm{Na}^{+} /$solvent co-intercalation during the first cycle which influence the energy required for following cycles. Interestingly, this potential shift does not appear in the charge (desodiation) process of BCNFs (Figure 1) either in that of graphite electrodes. ${ }^{34}$ Following with the discharge of BCNF electrodes, the sodiation plateau (III), which leads to very sharp peaks in the differential capacity plots, occurs at potentials around $0.60-0.65 \mathrm{~V}$ vs Na/Na ${ }^{+}$. Furthermore, although an appreciable loss of capacity (irreversible capacity) after the first discharge cycle was detected for BCNF electrodes (Figure 1), the irreversible consumption of $\mathrm{Na}^{+}$ occurs mainly at potentials below $0.6 \mathrm{~V}$. Specifically, the sodiation peak around 0.5 $\mathrm{V}$ in the differential capacity plots basically disappears after the first cycle.

In light of the results described so far, it is obvious that the electrochemical sodiation mechanism of BCNF materials relies on the potential region. To study this mechanism, the equation $i=a v^{b}$, which related the measured current $i(\mathrm{~A})$ and the scan rate $v\left(\mathrm{mV} \mathrm{s}^{-1}\right)$, was applied to the cyclic voltammetry data of BCNF electrodes acquired at several rates $\left(0.2,0.5,1.0,1.5,2.0\right.$ and $\left.3.0 \mathrm{mV} \mathrm{s}^{-1}\right)$. In this equation, $b$ is the slope of the linear line produced by plotting $\log i v s \log v$, and its value $(0.5-1.0)$, is determined by the current origin, i. e. the type of sodiation 
process. Thus, $a b$ value of 0.5 means that the sodiation occurs primarily by an intercalation controlled by a diffusion process; while in contrast, a value of 1.0 indicates that sodiation mechanism is mostly surface-limited capacitive. ${ }^{19,29,35}$ As an example of this parameter calculation, Figure $2 \mathrm{a}$ shows the second cycle voltammograms, at different scan rates, of BCNF167/28 electrode (CV profiles of others BCNF electrodes are showed in the Figure S3 of the Supporting Information); whereas the corresponding $\log i v s \log v$ plots for the cathodic (sodiation) peaks $1,2,3,4$ and 5 as well as the linear lines slope ( $b$ values) appear in Figure 2b. For this particular electrode, $b$ parameter varies from $a$ minimum value of 0.61 (peak 2) to a maximum of $0.92-0.94$ (peaks 3-5) which, as mentioned, are associated with predominant intercalation and capacitive sodium storage mechanisms, respectively. Moreover, a $b$ value of 0.76 was calculated for peak 1 suggesting a combination of both sodium storage mechanisms. The $b$ data for the cathodic (sodiation) peaks of some BCNF electrodes (from CVs at the scan rate of $0.2 \mathrm{mV} \mathrm{s}^{-1}$, Figures 2 and S3) are plotted against the corresponding potential vs $\mathrm{Na} / \mathrm{Na}^{+}$in Figure 3. At potentials $<0.2 \mathrm{~V}$, the sodium storage in the electrodes goes through different combinations of capacitive and intercalation mechanisms as shown by the values of the $b$ parameter which range from 0.73 for BCNF16/28 to 0.89 for BCNF27`5/28. However, at potentials $>0.7 \mathrm{~V}$, the capacitive mechanism appears predominant since $b$ is mostly higher than 0.9 . Unlike this, in the middle potential region $(\sim 0.6 \mathrm{~V})$, intercalation is the predominant sodiation mechanism in a majority of the electrodes. However, this prevalence depends on the graphitic degree of BCNF materials as assessed by XRD (Table I). Thus, $b$ values around 0.6 (predominant intercalation) were calculated for electrodes based on BCNF materials with interlayer distances, $\mathrm{d}_{002}$, of $\sim 0.336 \mathrm{~nm}$ 
(p. e. BCNF167/28 or BCNF175/28), whereas for those from BCNF16/26 or BCNF16/28 with $d_{002}$ values of $\sim 0.340 \mathrm{~nm}$, the sodiation mechanism is mainly capacitive $(b \sim 0.9)$. It is therefore evident from these results that the decrease of the available space between the graphene layers (i. e. increase of the material graphitic degree) promotes the storage of the $\mathrm{Na}^{+}$ions by a diffusion-controlled intercalation process at potentials around $0.6 \mathrm{~V}$ (Figure 3). In any case, it can be inferred from the discussion of the $b$ parameter data that a considerable amount of the cathodic current measured for BCNF electrodes comes from a capacitive (surface-limited) sodiation process. Taking into account the graphite-like structure and small surface area $\left(\mathrm{S}_{\mathrm{BET}}\right)$ of $\mathrm{BCNF}$ materials (Table I), the capacitive current is principally attributable to a pseudocapacitive intercalation process resulting from the intercalation of $\mathrm{Na}^{+}$ions into the graphene layers accompanied by a faradaic charge-transfer. ${ }^{17,36}$ Therefore, the total measured cathodic current of BCNF electrodes comes from different combinations of pseudocapacitive intercalation $(\mathrm{Cl})$ and diffusion-controlled intercalation (DCl) current types. The current response $i(\mathrm{~A})$ at a specific potential and $v\left(\mathrm{mV} \mathrm{s}^{-1}\right)$ scan rate follows the equation $i$ $=k_{1} v+k_{2} v^{1 / 2}$ in which the first $\left(k_{1} v\right)$ and second $\left(k_{2} v^{1 / 2}\right)$ addends correspond to $\mathrm{Cl}$ and $\mathrm{DCl}$ currents, respectively, whereas $k_{1}$ and $\mathrm{k}_{2}$ are constants. ${ }^{19,29,35,36}$ For calculation purposes, it was applied to $\mathrm{CV}$ data of BCNF electrodes as $i / v^{1 / 2}=$ $k_{1} v^{1 / 2}+k_{2}$. Based on the former equation, the scan rate dependence of the current for the sodiation peaks 1 to 5 and 1 to 6 of BCNF16/16 and BCNF175/28 electrodes is plotted in Figure 4. Linear relationships between $i / v^{1 / 2}$ and $v^{1 / 2}$ were obtained for all peaks from which the slope $k_{1}$ and $y$-axis intercept point $k_{2}$ were determined and afterwards, used for the calculation of the corresponding $\mathrm{Cl}$ and $\mathrm{DCl}$ contributions to the measured sodiation current which are also shown in 
Figure 4 (data for other BCNF electrodes is provided in Table SIl of Supporting Information). At the lowest potentials $(<0.2 \mathrm{~V})$, the diffusion-controlled sodium intercalation appears moderately predominant for some BCNF electrodes (DCI currents 60-69 \%, Table SII), whereas for others such as BCNF16/26 and BCNF175/28 in Figure 4, the contribution of the sodium capacitive intercalation is slightly higher ( $\mathrm{Cl}$ currents $56-57 \%)$. In any event, the differences between BCNF electrodes at this low potential are modest. However, in the intermediate potential $(\sim 0.6 \mathrm{~V}), \mathrm{DCl}$ contributions from up to $91 \%$, which point out that the sodiation comes essentially by diffusion-controlled intercalation, to only $24 \%$ were calculated for BCNF175/28 and BCNF16/26, respectively. These results are consistent with $b$ data in Figure 3 from which the dependency of the sodiation mechanism at this intermediate potential on the graphitic degree of BCNF materials was inferred. Thus, $\mathrm{DCl}$ values $\geq 80 \%$ were determined for those with interlayer spacing, $\mathrm{d}_{002} \leq 0.372 \mathrm{~nm}$ (Figure 4, Tables I and SII). As expected from $b$ values, at high potentials $(>0.7 \mathrm{~V}), \mathrm{Cl}$ current contributions are predominant showing percentages $>90 \%$ in many of the sodiation peaks, particularly in those electrodes from materials such as BCNF16/26 and BCNF16/28 with larger distances between graphene layers $\left(d_{002} \sim 0.340 \mathrm{~nm}\right)$, thus facilitating the capacitive intercalation of the sodium ions.

To analyse the results of sodium storage on BCNF electrodes as a whole rather than as a function of the potential, the quantitative capacitive $\mathrm{Cl}_{\mathrm{T}}$ and diffusion-controlled intercalation $\mathrm{DCl}_{\mathrm{T}}$ contributions to the total measured cathodic current, in a typical $\mathrm{CV}$ at the scan rate of $0.2 \mathrm{mV} \mathrm{s}^{-1}$, were calculated from data in Tables SI (loads of BCNF electrodes) and SII (contributions of CI and DCI currents for cathodic peaks of BCNF electrodes, those of BCNF16/26 and BCNF175/28 
electrodes are in Figure 4) by comparing the corresponding areas (see Figure S4 of Supporting Information) and they are reported in Table $\mathrm{II} . \mathrm{Cl}_{\mathrm{T}} / \mathrm{DCl} \mathrm{I}_{\mathrm{T}}$ ratios from 2.5 (sodiation occurs primarily by capacitive intercalation) to 0.4 (a significant amount of the stored charge comes from a diffusion-controlled intercalation process) were determined for BCNF electrodes. From these ratios, it is evident that the increase of the materials graphitic degree promotes the intercalation of the $\mathrm{Na}^{+}$ions by a diffusion-controlled mechanism, particularly at potentials around 0.6 $\mathrm{V}$ as it has been discussed above (Figure 4, Tables I and SII).

Finally, to discern the origin of the appreciable loss of capacity (irreversible capacity) detected after the first cycle of BCNF electrodes (Figures 1 and SII), the dependence between measured current and scan rate $\left(i=a v^{b}\right)$ was applied to the sodiation peaks of the first cycle CVs of BCNF16/26 and BCNF175/28, and the corresponding $b$ parameter values were determined. These values together with those from the second cycle CV are plotted vs potential peaks (see Figure S5 in Supporting Information). As seen, at potentials $<0.8 \mathrm{~V}$ the $b$ values increases significantly after the first cycle (p. e. from $\sim 0.7$ to $\sim 1$ at $0.75 \mathrm{~V}$ in both electrodes). Therefore, it seems that the irreversible capacity showed by these electrodes arise substantially from a diffusion-controlled intercalation current loss.

\section{Capacity and cycling stability of graphitic BCNF electrodes: effect of} electrical current density. Galvanostatic cycling experiments of BCNF electrodes were initially performed at the relatively low electrical current density of $37.2 \mathrm{~mA} \mathrm{~g}^{-}$ 1 for 50 discharge-charge cycles. The main electrochemical parameters of all electrodes are summarized in Table III, and the specific capacity vs cycle number plots for some of them are shown in Figure 5. Capacity values around $100 \mathrm{mAh} \mathrm{g}^{-1}$ 
(being always referred to the active material mass) after 50 discharge-charge cycles, which are in the order of those reported for natural and oil-derived graphite electrodes in the same $1 \mathrm{M} \mathrm{NaOTf/DG}$ electrolyte ${ }^{16,18,37}$ as well as in different glyme-based electrolytes, ${ }^{20,24}$ were determined for most of the BCNF electrodes. The percentages of irreversible capacity (irreversible consumption of $\mathrm{Na}^{+}$) in the first discharge-charge cycle are in the range 55-80 \% (Table III). As concluded in the previous section, SEI formation is only subsidiary responsible for these large losses of capacity. Focusing on discharge capacity retention percentages in Table III, three electrode types can be distinguished, remarkable stable (BCNF16/28, BCNF161/28, BCNF165/28, BCNF167/28, BCNF177/28), stable (BCNF16/26, BCNF175/28, BCNF267/28, BCNF27*5/28) and slightly stable (BCNF277/28, BCNF27*7/28) with values of $\geq 85 \%, 69-76 \%$ and $<60 \%$, respectively. In general, BCNF electrodes having lower irreversible capacity (Table III) and/or a significant amount of the stored charge coming from a capacitive intercalation process (Table II) show better cycling stability. Since as stated above, the first cycle irreversible capacity of BCNF electrodes arises substantially from a diffusioncontrolled intercalation current loss, it is obvious that a part of the sodium remains intercalated at the end of the charge (desodiation) process and the corresponding proportion should increases as $\mathrm{C}_{\text {irr }}$ increases. This trapped intercalated sodium could affect subsequent sodiation cycles, thus leading to a discharge capacity decrease, particularly, in those electrodes in which the sodiation occurs mainly by a diffusion-controlled intercalation process.

The discharge capacity vs cycle number plots from the cycling at increasing electrical current density (from 18.6 to $744 \mathrm{~mA} \mathrm{~g}^{-1}$ ) of some BCNF electrodes are depicted in Figure 6. First of all, it should be remarked that this significant increase 
has basically not repercussion on the cycling behaviour of BCNF161/28 and BCNF167/28 electrodes. Thus, specific capacities around $100 \mathrm{mAh} \mathrm{g}^{-1}$ were provided by these electrodes with excellent cycle efficiencies (charge capacity/discharge capacity $>98 \%$ ) in the whole range of increasing current densities. BCNF16/26 electrode appears a little more sensitive to the increase of the electrical current, particularly, at the highest ones. Nevertheless, this electrode also shows stable capacities with $\mathrm{R}$ values $>95 \%$ at each of them. Furthermore, no electrode degradation occurs after cycling at the highest current density of 744 $\mathrm{mA} \mathrm{g}^{-1}$ as can be inferred from the $100 \%$ recovery of the initial capacity at 18.6 $\mathrm{mA} \mathrm{g}^{-1}$ when returning to these conditions. Therefore, these electrodes also have a noticeable ability to endure fast charge-discharge rates.

Prolonged galvanostatic cycling tests at very high electrical current densities (1.86 $\mathrm{A} \mathrm{g}^{-1}, 3.72 \mathrm{~A} \mathrm{~g}^{-1}, 7.44 \mathrm{~A} \mathrm{~g}^{-1}$ ) were conducted for BCNF electrodes to estimate the significance of this ability (rate capability). Plots of discharge capacity against cycle number for BCNF167/28 (up to 2500 cycles) and BCNF16/26 (up to 6000 cycles) electrodes are compiled in Figure 7. These electrodes exhibit outstanding capacity retentions (p. e. $100 \%$ after 2500 cycles at $7.44 \mathrm{~A} \mathrm{~g}^{-1}$ ) with coulombic efficiencies of $\sim 100 \%$. Moreover, specific capacities up to $83 \mathrm{mAh} \mathrm{g}^{-1}$ after 2500 cycles at $3.72 \mathrm{~A} \mathrm{~g}^{-1}$ or to $90 \mathrm{mAh} \mathrm{g}^{-1}$ after 1400 cycles at $1.86 \mathrm{~A} \mathrm{~g}^{-1}$ were determined for BCNF167/28 electrode (Figure 7a), which are approximately $84 \%$ and $91 \%$, respectively, of that delivered by this electrode at $37.2 \mathrm{~mA} \mathrm{~g}^{-1}$ after 50 cycles (Table III). This ultrahigh rate capability, comparable to that of supercapacitors, can be ascribed mainly to the intercalation of the $\mathrm{Na}^{+}$ions into graphitic BCNF electrodes by the capacitive mechanism $(\mathrm{Cl})$ as discussed in previous section, which improve their transportability through the graphene layers. 
Within this context, among others, the long-term excellent reversibility, long cycle life as well as rate performance of graphite electrodes in glyme-based electrolytes was attributed to the fact that $\mathrm{Na}^{+}$ions are electrochemically adsorbed into the graphene layer rather than be atomically bonded to carbon. ${ }^{17,20}$

\section{Conclusions}

The graphitic biogas-derived carbon nanofibers studied in this work have a unique combination of electrochemical properties, including suitable specific capacity at low and high electrical current densities, high rate capability, excellent cycle stability and coulombic efficiency as well as long cycle life $(\sim 6000$ cycles up to $7.5 \mathrm{~A} \mathrm{~g}^{-1}$ ), and renewable origin which make them adequate materials for anodes of sodium-ion batteries when using glyme-based electrolytes. These graphitic nanomaterials can provide up to $\sim 90 \mathrm{mAh} \mathrm{g}^{-1}$ at $1.7 \mathrm{~A} \mathrm{~g}^{-1}$ after 1500 cycles or to $\sim 85 \mathrm{mAh} \mathrm{g}^{-1}$ at $3.7 \mathrm{~A} \mathrm{~g}^{-1}$ after 2500 cycles with cycle efficiencies of $100 \%$ and capacity retentions $>90 \%$.

The sodiation of BCNFs occurs through different combinations of diffusioncontrolled intercalation $(\mathrm{DCl})$ and pseudocapacitive intercalation $(\mathrm{Cl})$ processes which contributions to the stored charge (cathodic measured current) depend mainly on the potential region. Regardless of BCNF electrode, at high potentials (> $0.7 \mathrm{~V})$, the $\mathrm{Cl}$ current is prevailing (>90\%) whereas at low potentials $(<0.2 \mathrm{~V})$ no significant differences are observed between them. However, in the intermediate potential $(\sim 0.6 \mathrm{~V})$, the graphitic structure of BCNFs clearly controls the sodiation process. Overall, at this potential the increase of the available space between the graphene layers (i. e. decrease of material graphitic degree) promotes the storage 
of the $\mathrm{Na}^{+}$ions by the capacitive intercalation mechanism, thus leading to $\mathrm{Cl}$ current percentages from only $9 \%$ to $76 \%$ for materials with $d_{002}$ values of 0.3361 $\mathrm{nm}$ and $0.3399 \mathrm{~nm}$, respectively. In any event, the quantitative contribution of the capacitive current to the total stored sodium in BCNF electrodes by considering the whole range of potential is noteworthy (28-71\%), which account for the ultrahigh rate performance of these electrodes because of the improvement of the transportability of the $\mathrm{Na}^{+}$ions through the graphene layers.

\section{Acknowledgements}

Financial support from the Spanish Ministry of Economy and Competitiveness MINECO (Project ENE2014-52189-C2-2-R) and Iberdrola Spain Foundation (www.fundacioniberdrola.org, Project 2016-2017) is gratefully acknowledged. I. Cameán and J. Rodríguez-García, respectively, thank funding from Fundación General CSIC (Programa ComFuturo) and from MINECO for a Ph.D. fellowship (FPI BES 2015-071293) to develop the work.

\section{References}

1. Office of electricity delivery and energy reliability - United States Department of Energy (DOE), Global energy storage database, www.energystorageexange.org, (2018). 
2. M. D. Slater, D. Kim, E. Lee, and C. S. Johson, Adv. Funct. Mater., 23, 947 (2013).

3. Y. Li, Y. Lu, C. Zhao, Y. S. Hu, M. M. Titirici, H. Li, X. Huan, and L. Chen, Energy Storage Materials, 7, 130 (2017).

4. D. Kundu, E. Talaie, V. Duffort, and L.F. Nazar, Angew. Chem. Int. Ed., 54, 3431 (2015).

5. P. K. Nayak, L. Yang, and W. Brehm, P. Adelhelm, Angew. Chem. Int. Ed., 56, 2 (2017).

6. L. Chen, M. Fiore, J. E. Wang, R. Ruffo, D. K. Kim, and G. Longoni, Adv. Sustainable Syst., 2, 1700153 (2018).

7. M. I. Jamesh, and A. S. Prakash, J Power Sources, 378, 268 (2018).

8. N. Yabuuchi, K. Kubota, M. Dahbi, and S. Komaba, Chem. Rev., 114, 11636 (2014).

9. L. P. Wang, L. Yu, X. Wang, M. Seinivasan, and Z. J. Xu, J. Mat. Chem. A, 3, 9353 (2015).

10. C. Bommier, and X. Ji, Small, 14, 1703576 (2018).

11. A. Ponrouch, D. Monti, A. Boschin, B. Steen, P. Johansson, and M. R. Palacin, J. Mat. Chem. A, 3, 22 (2015).

12. D. Monti, A. Ponrouch, M. R. Palacin, and P. Johansson, J. Power Sources, 324, 712 (2016).

13. P. Ge, and M. Fouletier, Solid State lonics, 28, 1172 (1988).

14. M. A. Muñoz-Márquez, D. Saurel, J. L. Gómez-Cámer, M. Casas-Cabanas, E. Castillo-Martínez, and T. Rojo, Adv. Energy Mater., 7, 1700463 (2017).

15. K. Nobuhara, H. Nakayama, M. Nose, S. Nakanishi, and H. Iba, J Power Sources, 243, 585 (2013). 
16. B. Jache, and P. Adelhem, Angew. Chem. Int. Ed., 53, 10169 (2014).

17. Z. Zhu, F. Cheng, Z. Hu, Z. Niu, J. Chen, J. Power Sources, 293, 626 (2015).

18. B. Jache, J. O. Binder, T. Abe, and P. Adelhelm, Phys. Chem. Chem. Phys., 18, 14299 (2016).

19. H. Kim, J. Hong, Y. U. Park, J. Kim, I. Hwang, K. Kang, Adv. Funct. Mat., 25, 534 (2015).

20. H. Kim, J. Hong, G. Yoon, H. Kim, K. Y. Park, M. S. Park et al., Energy Enviro. Sci., 8, 2963 (2015).

21. T. Kajita, and T. Itoh, Phys. Chem. Chem. Phys., 20, 2188 (2016).

22. J. Rodríguez-García, I. Cameán, A. Ramos, E. Rodríguez, and A. B. García, Electrochim. Acta, 270, 236 (2018).

23. A. Rudola, K. Du, and P. Balaya, J. Electrochem. Soc., 164, A1098 (2017).

24. I. Hasa, X. Dou, D. Buchholz, Y. Shao-Horn, J. Hassoun, S. Passerini and B. Scrosati, J. Power Sources, 310, 26 (2016).

25. R. Schmuch, R. Wagner, G. Hörpel, T. Placke, M. Winter, Nature Energy, 3, $267(2018)$

26. S. de Llobet, J. L. Pinilla, R. Moliner, I. Suelves, J. Arroyo, F. Moreno, M. Muñoz, C. Monné, I. Cameán, A. Ramos, N. Cuesta, and A. B. García, Int. J. Hydrogen Energy, 38, 15084 (2013).

27. N. Cuesta, I. Caméan, A. Ramos, S. de Llobet, and A. B. García, Fuel Process. Technol., 152, 1 (2016).

28. N. Cuesta, I. Cameán, A. Ramos, and A. B. García, Electrochim. Acta, 222, 264 (2016).

29. J. Wang, J. Polleux, J. Lim, and B. Dunn, J. Phys. Chem. C, 111, 14925 (2007). 
30. A. Cuesta, P. Dhamelincourt, J. Laureyns, A. Martinez-Alonso, and J. M. D. Tascon, J. Mater. Chem., 8, 2875 (1998).

31. I. Cameán, and A. B. Garcia, J. Power Sources, 196, 4816 (2011).

32. J. Biscoe, and B. E. Warren, J. Appl. Phys., 13, 364 (1942).

33. M. Goktas, C. Bolli, E. J. Berg, P. Novák, K. Pollok, F. Langenhorst, M. V. Roeder, O. Lenchuk, D. Mollehauer, P. Adelhelm, Adv. Energy Mater., 8, 1702724 (2018).

34. J. Maibach, F. Jeschull, D. Brandell, K. Edström, and M. Valvo, App. Mater. Interfaces, 9, 12373 (2017).

35. H. Lindström, S. Södergen, A. Solbrand, H. Rensmo, J. Hjelm, A. Hagfeldt and A. Hagfeldt, J. Phys. Chem. B, 101, 7717 (1997).

36. V. Augustyn, P. Simon, and B. Dunn, Energy Environ. Sci., 7, 1597 (2014).

37. M. Cabello, X. Bai, T. Chyrka, G. F. Ortiz, P. Lavela, R. Alcántara, and J. L. Tirado, J. Electrochem. Soc., 164, A3804 (2017). 


\section{Tables}

Table I. Structural $\left(d_{002}, L_{c}, L_{a}\right)$ and textural parameters $\left(S_{B E T}, V_{T}\right)$ of the graphitic biogas-derived carbon nanofibers (BCNFs).

\begin{tabular}{lcrccc} 
BCNFs & $\mathrm{d}_{002} / \mathrm{nm}$ & $\mathrm{L}_{d} / \mathrm{nm}$ & $\mathrm{L}_{\mathrm{a}} / \mathrm{nm}$ & $\mathrm{S}_{\mathrm{BET}} / \mathrm{m}^{2} \mathrm{~g}^{-1}$ & $\mathrm{~V}_{\mathrm{T}} / \mathrm{cm}^{3} \mathrm{~g}^{-1}$ \\
\hline BCNF16/26 & 0.3399 & 10.5 & 36.9 & 39 & 0.194 \\
BCNF16/28 & 0.3398 & 10.5 & 37.7 & 38 & 0.191 \\
BCNF161/28 & 0.3397 & 10.1 & 39.6 & 44 & 0.217 \\
BCNF165/28 & 0.3372 & 19.8 & 50.3 & 33 & 0.161 \\
BCNF167/28 & 0.3362 & 35.4 & 99.6 & 21 & 0.103 \\
BCNF175/28 & 0.3361 & 40.9 & $>100.0$ & 59 & 0.169 \\
BCNF177/28 & 0.3360 & 46.8 & $>100.0$ & 33 & 0.107 \\
BCNF267/28 & 0.3370 & 21.6 & 55.9 & 37 & 0.123 \\
BCNF277/28 & 0.3364 & 31.1 & 62.9 & 45 & 0.130 \\
BCNF27*5/28 & 0.3363 & 46.2 & 98.0 & 47 & 0.146 \\
BCNF27*7/28 & 0.3363 & 48.3 & $>100.0$ & 36 & 0.114 \\
\hline
\end{tabular}

$d_{002}$, interlayer spacing; $L_{c}$ and $L_{a}$ mean crystallite sizes along $c$ and a axes; $\mathrm{S}_{\mathrm{BET}}$, surface area; $\mathrm{V}_{\mathrm{T}}$, total pore volume. 
Table II. Pseudocapacitive intercalation $\mathrm{Cl}_{\mathrm{T}}$ and diffusion-controlled intercalation $\mathrm{DCl}_{\mathrm{T}}$ contributions to the total stored charge in the sodiation of BCNF electrodes calculated from data in Figure 4 and Table SII.

\begin{tabular}{lcc}
$\begin{array}{c}\text { BCNF } \\
\text { Electrodes }\end{array}$ & $\mathrm{Cl}_{\mathrm{T}}(\%)$ & $\mathrm{DCl}_{\mathrm{T}}(\%)$ \\
\hline $\mathrm{BCNF16/26}$ & 71 & 29 \\
$\mathrm{BCNF16/28}$ & 68 & 32 \\
$\mathrm{BCNF161/28}$ & 54 & 46 \\
$\mathrm{BCNF167/28}$ & 32 & 68 \\
$\mathrm{BCNF175/28}$ & 28 & 72 \\
$\mathrm{BCNF267/28}$ & 35 & 65 \\
$\mathrm{BCNF277/28}$ & 31 & 69 \\
$\mathrm{BCNF27} 5 / 28$ & 35 & 65 \\
$\mathrm{BCNF27} 7 / 28$ & 34 & 66 \\
\hline
\end{tabular}


Table III. Specific discharge $\left(C_{\text {disc }}\right)$ and charge $\left(C_{\text {charge }}\right)$ capacities in the $1^{\text {st }}, 2^{\text {nd }}$ and $50^{\text {th }}$, cycles, irreversible capacity in the $1^{\text {st }}$ cycle $\left(\mathrm{C}_{\mathrm{irr}}\right)$ and capacity retention $(\mathrm{R})$ parameters from the galvanostic cycling of graphitic biogas-derived carbon nanofibers (BCNFs) electrodes in 1M NaOTf in diglyme electrolyte (NaOTf/DG), at an applied electrical current density of $37.2 \mathrm{~mA} \mathrm{~g}^{-1}$.

\begin{tabular}{|c|c|c|c|c|c|}
\hline $\begin{array}{c}\text { BCNF } \\
\text { Electrodes }\end{array}$ & $\begin{array}{c}\mathrm{C}_{\text {disc }}-\mathrm{C}_{\text {charge }} / \mathrm{mAh} \mathrm{g}^{-1} \\
\left(1^{\mathrm{st}} \text { cycle }\right)\end{array}$ & $\begin{array}{c}\mathrm{C}_{\text {disc }}-\mathrm{C}_{\text {charge }} / \mathrm{mAh}^{-1} \\
\left(2^{\text {nd }} \text { cycle }\right)\end{array}$ & $\begin{array}{c}C_{\text {disc }}-C_{\text {charge }} / \mathrm{mAh} \mathrm{g}^{-1} \\
\left(50^{\text {th }} \text { cycle }\right)\end{array}$ & $\begin{array}{c}\mathrm{C}_{\text {irr }} / \% \\
\left(1^{\text {st }} \text { cycle }\right)^{a}\end{array}$ & $\begin{array}{c}\mathrm{R} / \% \\
\left(2^{\text {nd }}-50^{\text {th }} \text { cycles }\right)^{\mathrm{b}}\end{array}$ \\
\hline BCNF16/26 & $250-112$ & $148-110$ & $102-106$ & 55 & 69 \\
\hline BCNF16/28 & $349-77$ & $107-76$ & $92-79$ & 78 & 86 \\
\hline BCNF161/28 & $265-86$ & $103-88$ & $102-98$ & 67 & 99 \\
\hline BCNF165/28 & $270-91$ & $110-92$ & $101-96$ & 66 & 92 \\
\hline BCNF167/28 & $219-92$ & $117-94$ & $99-95$ & 58 & 84 \\
\hline BCNF175/28 & $354-98$ & $140-98$ & $98-87$ & 72 & 70 \\
\hline BCNF177/28 & $227-92$ & $107-92$ & $91-87$ & 59 & 85 \\
\hline BCNF267/28 & $300-82$ & $124-84$ & $94-86$ & 73 & 76 \\
\hline BCNF277/28 & $514-103$ & $213-103$ & $98-84$ & 80 & 46 \\
\hline BCNF27*5/28 & $355-77$ & $129-78$ & $94-74$ & 78 & 73 \\
\hline BCNF27*7/28 & $412-83$ & $170-82$ & $97-80$ & 80 & 57 \\
\hline
\end{tabular}

a Irreversible capacity $(\%)=\left[\mathrm{C}_{\text {disc }}\left(1^{\text {st }}\right.\right.$ cycle $)-\mathrm{C}_{\text {charge }}\left(1^{\text {st }}\right.$ cycle $\left.)\right]\left[\mathrm{C}_{\text {disc }}\left(1^{\text {st }} \text { cycle }\right)\right]^{-1} \times 100$

${ }^{b}$ Capacity retention $(\%)=\left[\mathrm{C}_{\text {disc }}\left(50^{\text {th }}\right.\right.$ cycle $\left.)\right]\left[\mathrm{C}_{\text {disc }}\left(2^{\text {nd }} \text { cycle }\right)\right]^{-1} \times 100$ 


\section{Captions for figures}

Figure 1. Potential profiles of the galvanostatic cycling at $37.2 \mathrm{~mA} \mathrm{~g}^{-1}$ of BCNF161/28, BCNF165/28, BCNF175/28 and BCNF177/28 electrodes in $\mathrm{NaOTf/DG}$ electrolyte (left) and the corresponding differential capacity plots (right).

Figure 2. BCNF167/28 electrode: (a) Second cycle voltammograms at 0.2 to 3.0 $\mathrm{mV} \mathrm{s}^{-1}$ and (b) $b$ value (line slope) determination from the power law dependence of current $i(\mathrm{~A})$ on scan rate $v\left(\mathrm{mV} \mathrm{s}^{-1}\right)$ of the cathodic (sodiation) peaks 1 to 5 .

Figure 3. Variation of $b$ data with potential vs $\mathrm{Na} / \mathrm{Na}^{+}$for cathodic peaks (from CVs at the scan rate of $0.2 \mathrm{mV} \mathrm{s}^{-1}$ ) of BCNF electrodes.

Figure 4. Scan rate $v\left(\mathrm{mV} \mathrm{s}^{-1}\right)$ dependence of the current $i(\mathrm{~A})$ for the cathodic peaks (sodiation) (see Figure S2) of BCNF16/26 and BCNF175/28 electrodes according to the equation $i / v^{1 / 2}=k_{1} v^{1 / 2}+k_{2}$ [ref. 34], and calculated contributions of pseudocapacitive intercalation $(\mathrm{Cl})$ and diffusion-controlled intercalation (DCl) currents to the total measured current for each peak at the scan rate of $0.2 \mathrm{mV} \mathrm{s}^{-1}$. Figure 5. Specific discharge/charge capacity and coulombic efficiency vs cycle number plots from the galvanostatic cycling at $37.2 \mathrm{~mA} \mathrm{~g}^{-1}$ of BCNF161/28, BCNF165/28 and BCNF177/28 electrodes in NaOTf/DG electrolyte.

Figure 6. Discharge capacity vs cycle number plots from the galvanostatic cycling at variable electrical current density (from 18.6 to $744 \mathrm{~mA} \mathrm{~g}^{-1}$, and back to $18.6 \mathrm{~mA}$ $\mathrm{g}^{-1}$ ) of BCNF16/26, BCNF161/28 and BCNF167/28 electrodes.

Figure 7. Discharge capacity vs cycle number plots from the prolonged galvanostatic cycling at high electrical current densities of $1.86,3.72$ and $7.44 \mathrm{~A} \mathrm{~g}^{-}$ ${ }^{1}$ of (a) BCNF167/28 and (b) BCNF16/26 electrodes. 


\section{FIGURE 1}
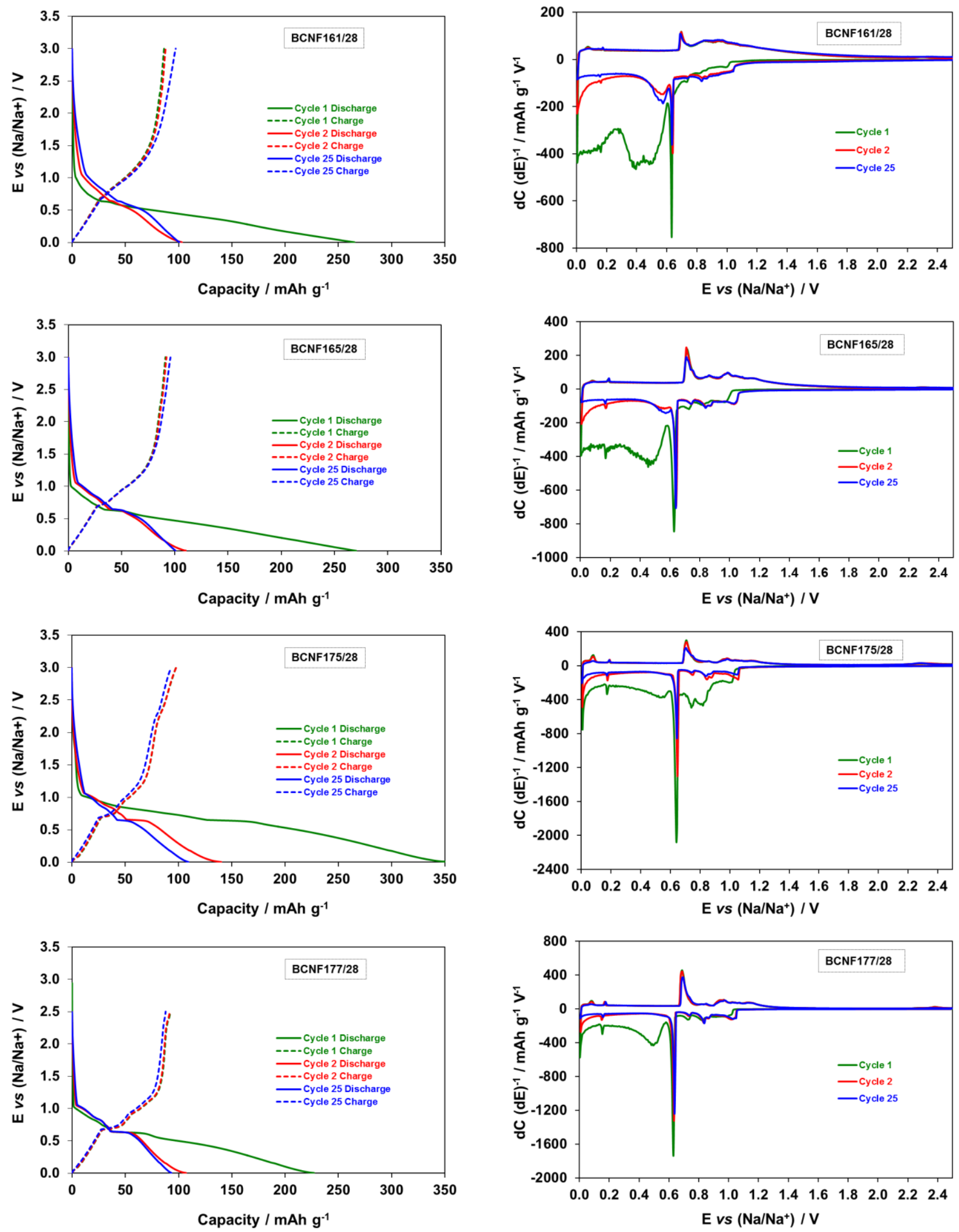

Figure 1. Potential profiles of the galvanostatic cycling at $37.2 \mathrm{~mA} \mathrm{~g}^{-1}$ of $B C N F 161 / 28$, BCNF165/28, BCNF175/28 and BCNF177/28 electrodes in NaOTf/DG electrolyte (left) and the corresponding differential capacity plots (right). 


\section{FIGURE 2}
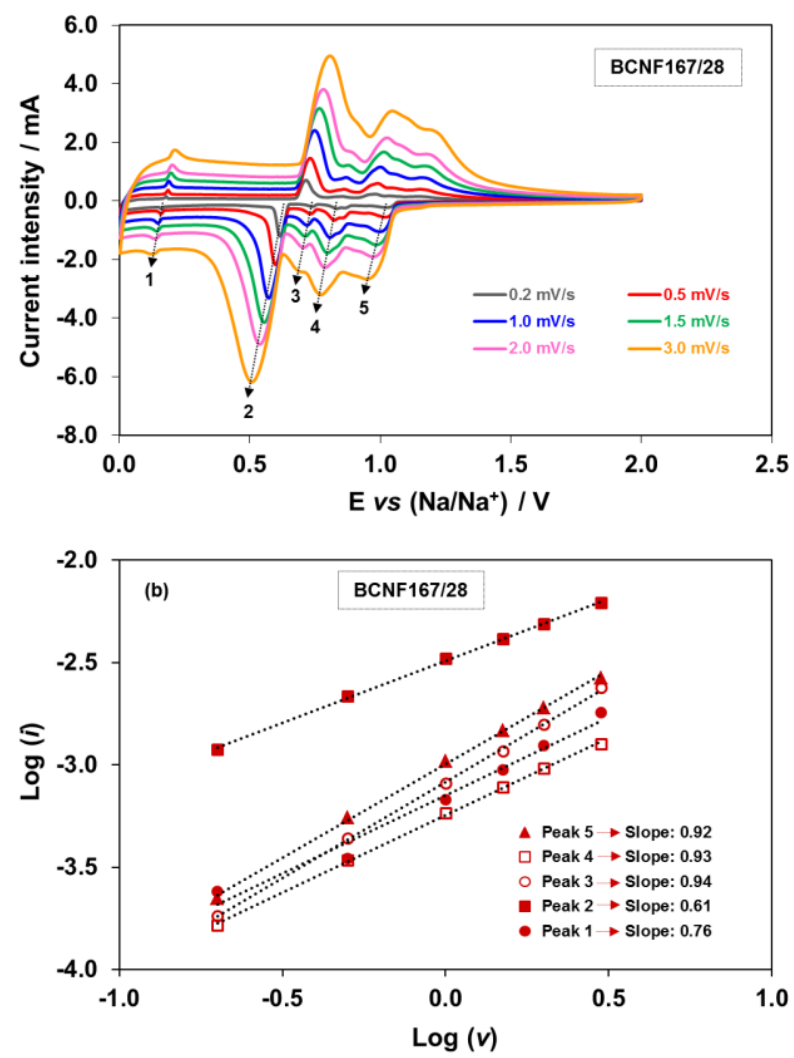

Figure 2. BCNF167/28 electrode: (a) Second cycle voltammograms at 0.2 to $3.0 \mathrm{mV} \mathrm{s}^{-1}$ and (b) $b$ value (line slope) determination from the power law dependence of current $i(\mathrm{~A})$ on scan rate $v$ $\left(\mathrm{mV} \mathrm{s}^{-1}\right)$ of the cathodic (sodiation) peaks 1 to 5 . 


\section{FIGURE 3}

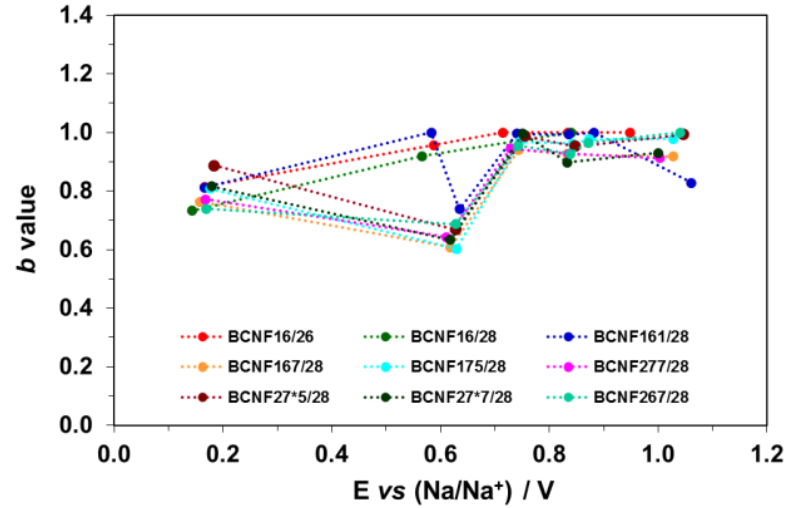

Figure 3. Variation of $b$ data with potential vs $\mathrm{Na} / \mathrm{Na}^{+}$for cathodic peaks (from CVs at the scan rate of $0.2 \mathrm{mV} \mathrm{s}^{-1}$ ) of BCNF electrodes. 


\section{Figure 4}
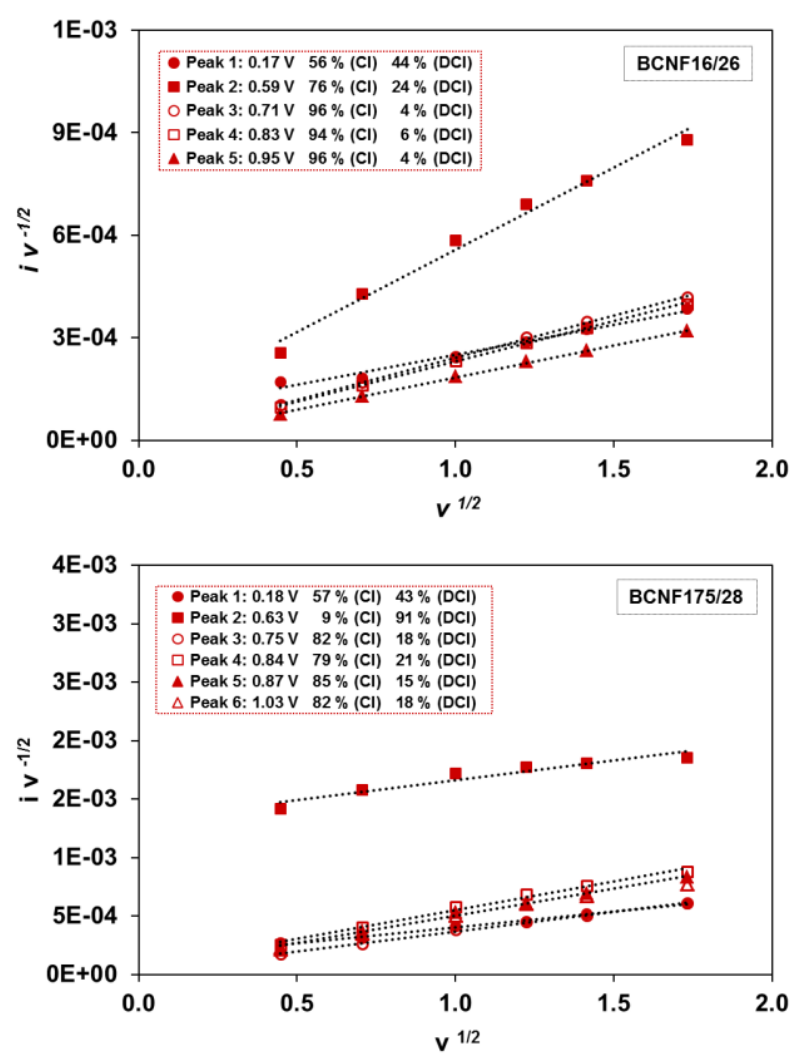

Figure 4. Scan rate $v\left(\mathrm{~mA} \mathrm{~s}^{-1}\right)$ dependence of the current $i(\mathrm{~A})$ for the cathodic peaks (sodiation) (see Figure S3) of BCNF16/26 and BCNF175/28 electrodes according to the equation $i / v^{1 / 2}=k_{1}$ $v^{1 / 2}+k_{2}$ [ref. 34], and calculated contributions of pseudocapacitive intercalation $(\mathrm{Cl})$ and diffusion-controlled intercalation (DCl) currents to the total measured current for each peak at the scan rate of $0.2 \mathrm{mV} \mathrm{s}^{-1}$. 


\section{FIGURE 5}

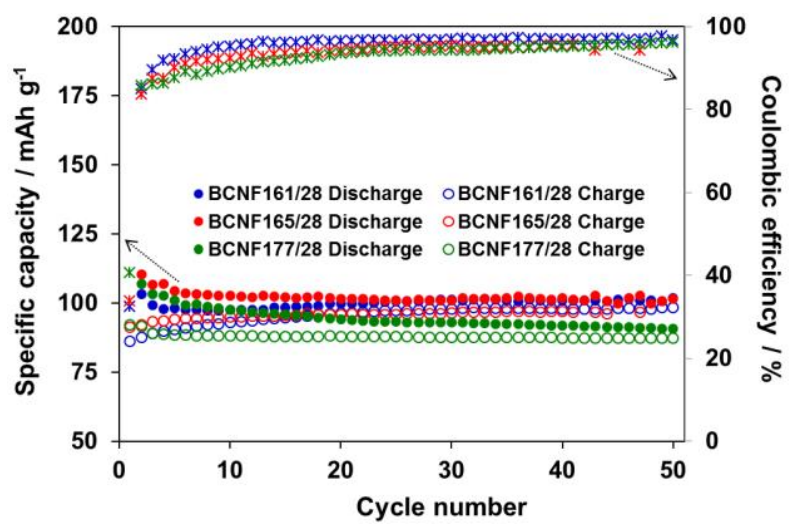

Figure 5. Specific discharge/charge capacity and coulombic efficiency vs cycle number plots from the galvanostatic cycling at $37.2 \mathrm{~mA} \mathrm{~g}^{-1}$ of BCNF161/28, BCNF165/28 and BCNF177/28 electrodes in NaOTf/DG electrolyte. 


\section{FIGURE 6}

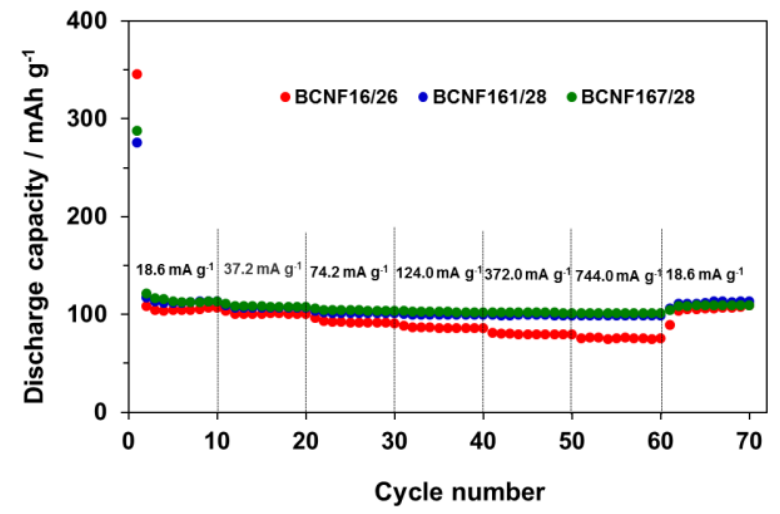

Figure 6. Discharge capacity vs cycle number plots from the galvanostatic cycling at variable electrical current density (from 18.6 to $744 \mathrm{~mA} \mathrm{~g}^{-1}$, and back to $18.6 \mathrm{~mA} \mathrm{~g}^{-1}$ ) of BCNF16/26, BCNF161/28 and BCNF167/28 electrodes. 
FIGURE 7
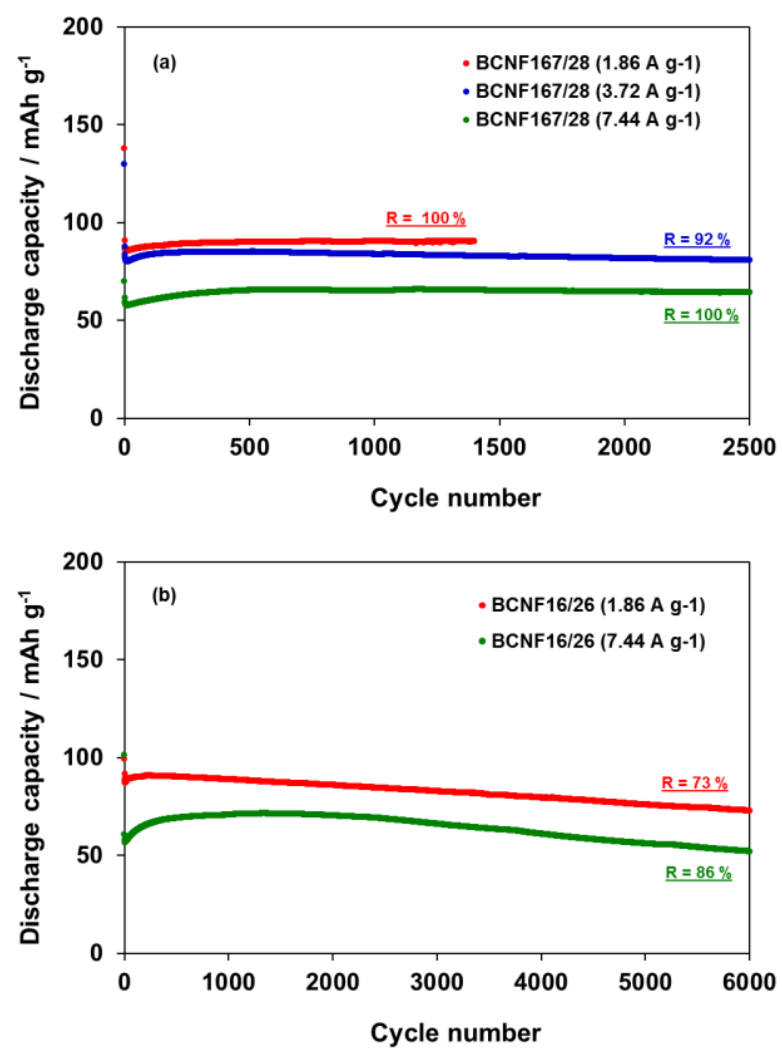

Figure 7. Discharge capacity vs cycle number plots from the prolonged galvanostatic cycling at high electrical current densities of 1.86, 3.72 and $7.44 \mathrm{~A} \mathrm{~g}^{-1}$ of (a) BCNF167/28 and (b) BCNF16/26 electrodes. 
